\title{
Commentary to: Atypical Presentation of Gastrointestinal Stromal Tumours-A Case Report by Kalpana Raja et al.
}

\author{
Dharmendra Mehta
}

Received: 19 March 2014 / Accepted: 1 April 2014 / Published online: 14 May 2014

(C) Association of Surgeons of India 2014

Dear Sir,

I read the case report "ATYPICAL PRESENTATION OF GASTROINTESTINAL STROMAL TUMOURS -A CASE REPORT" written by authors: Kalpana Raja, Bhawna Dev, Roy Santosham, and Joseph Santhosh, which was received 26th Feb. 2010/Accepted 4th June 2012/Published on line: 21st June 20127 Print Publication in Indian J Surg ( June 2013) 75 (suppl 1): S185-S187.

It is really confusing whether gastrointestinal stromal tumors (GIST) are benign or highly malignant. Authors in their case report mention that GIST are benign mesenchymal tumours of gastrointestinal tract, as per the Abstract and their Discussion, while in their conclusion they mention that GISTs are highly malignant.

Hence, I would like to draw the attention of authors that, essentially, to start with, GISTs are benign when they are microscopic or very small, i.e., $<2 \mathrm{~cm}$ in size, if arising from stomach and are usually incidentally detected but when they attain large size or they become symptomatic they are mostly malignant GIST. According to NCCN Guidelines 2014, most GISTs behave in an indolent manner, and those smaller than $2 \mathrm{~cm}$ in size are almost universally benign, but similar lesions of small intestine tend to be more aggressive than Gastric GISTs. So, tumor size less than or equivalent to $2 \mathrm{~cm}$ with a mitotic rate of 5 mitosis per 50 high-power field on microscopic examination are to be considered as benign; otherwise, most are considered as malignant GISTs [1].

Secondly, GISTs are the most common mesenchymal neoplasms of the gastrointestinal tract resulting from mutation in one of the receptor protein tyrosin kinase (KIT — called CD 117).Most GISTs (90-95 \%) are KIT-positive; hence, CD 117 is quite diagnostic of GIST, but it does not mean that CD 117 positivity is associated with malignant behavior of GIST. Also, CD 117 is the most important immunohistochemical marker than CD 34 which is positive in $<80 \%$ cases of GIST [2-4].

\section{Reference}

1. NCCN Guide Lines (2014). NCCN Clinical Practice Guidelines in Oncology—Soft Tissue Sarcoma Version 1. 2014. MS19-MS31

2. NCCN Guide Lines (2014). NCCN Clinical Practice Guidelines in Oncology_Soft Tissue Sarcoma Version 1. 2014. GIST B

3. Hornick JL, Fletcher CD (2007) The role of KIT in the management of patients with gastrointestinal stromal tumors. Hum Pathol 38(5):679687

4. Miettinen M, Kopczynski J, Makhlouf HR, Sarlomo-Rikala M, Gyorffy H, Burke A, Sobin LH, Lasota J (2003) Gastrointestinal stromal tumors, intramural leiomyomas, and leiomyosarcomas in the duodenum: a clinicopathologic, immunohistochemical and molecular genetic study of 167 cases. Am J Surg Pathol 27(5):625-641

D. Mehta $(\bowtie)$

Department of Surgical Oncology, Sri Aurobindo

Medical College \& P.G. Institute, Indore, India

e-mail: dymehta@gmail.com

D. Mehta

e-mail: dymehta@yahoo.co.uk 